\title{
Artigo/Article
}

\section{Avaliação clínica e micológica de onicomicose em pacientes brasileiros com HIV/AIDS}

\section{Clinical and mycological evaluation of onychomycosis among Brazilian HIV/AIDS patients}

\author{
Idalina Inês Fonsêca Nogueira Cambuim ${ }^{1}$, Danielle Patrícia Cerqueira Macêdo ${ }^{1}$, Marília Delgado ${ }^{2}$, \\ Kedma de Magalhães Lima ${ }^{1,3}$, Genilda Pereira Mendes ${ }^{1}$, Cristina Maria de Souza-Motta ${ }^{1}$, Débora Maria Massa Lima ${ }^{1}$, \\ Maria José Fernandes ${ }^{1}$, Oliane Maria Correia Magalhães ${ }^{1}$, Lusinete Acioli de Queiroz ${ }^{1+}$ e Rejane Pereira Neves $^{1}$
}

\begin{abstract}
RESUMO
Introdução: Onicomicoses são comuns em pacientes imunocomprometidos embora espécies emergentes tenham sido verificadas, modificado o perfil epidemiológico desta micose. Assim, o objetivo desta pesquisa é avaliar o perfil clínico e micológico da onicomicose em pacientes com infecção pelo HIV/AIDS. Métodos: Amostras clínicas foram coletadas, processados para exame direto e a cultura mantida a temperatura de $30^{\circ} \mathrm{C}$ e $37^{\circ} \mathrm{C}$ durante 15 dias. Resultados: Dos 100 pacientes, 32 apresentavam onicomicose. Os agentes isolados foram Candida albicans, C. parapsilosis, C. tropicalis, C. guilliermondii, Trichophyton rubrum, T. mentagrophytes, Fusarium solani, Scytalidium hialinum, S. japonicum, Aspergillus niger, Cylindrocarpon destructans e Phialophora reptans. Conclusões: Onicomicoses em HIV/AIDS apresentam variadas manifestações clínicas e podem ser causadas por fungos emergentes. As peculiaridades apresentadas pelos diferentes agentes de origem fúngica justificam a necessidade de identificação ao nível da espécie, com a finalidade de orientar uma melhor abordagem terapêutica e minimizar a exposição desses pacientes a condições de risco de uma infecção disseminada.
\end{abstract}

Palavras-chaves: Onicomicose. HIV/AIDS. Leveduras. Fungos filamentosos.

\begin{abstract}
Introduction: Onychomycosis is common in immunocompromised patients, but emerging species have been verified, thereby modifying the epidemiological profile of this mycosis. Thus, the aim of this study was to evaluate clinical and mycological profile of onychomycosis among HIV/AIDS patients. Methods: Clinical samples were collected and processed for direct examination, and cultures were maintained at a temperature of $30^{\circ} \mathrm{C}$ and $37^{\circ} \mathrm{C}$ for 15 days. Results: Out of 100 patients, 32 had onychomycosis. The etiological agents isolated were Candida albicans, C. parapsilosis, C. tropicalis, C. guilliermondii, Trichophyton rubrum, T. mentagrophytes, Fusarium solani, Scytalidium hialinum, S. japonicum, Aspergillus niger, Cylindrocarpon destructans and Phialophora reptans. Conclusions: Onychomycosis in HIV/AIDS patients presents various clinical manifestations and may be caused by emerging fungi. The peculiarities presented by different fungal agents justify the need for identification to species level, with the purpose of guiding better therapeutic approaches and minimizing these patients' exposure to conditions presenting a risk of disseminated infection
\end{abstract}

Keywords: Onychomycosis. HIV/AIDS. Yeasts. Filamentous fungi.

1. Departamento de Micologia, Universidade Federal de Pernambuco, Recife, PE. 2. Ambulatório de Dermatologia, Hospital Correia Picanço, Recife, PE. 3. Serviço de Micologia, NKB-Medicina Diagnóstica, Recife, PE. †In mem,orian

Endereço para correspondência: Drª Rejane Pereira Neves. Depto de Micologia/UFPE. Av. Prof. Nelson Chaves s/n, Cidade Universitária, 50670-420 Recife, PE.

Tel: 5581 2126-8481; Fax: 5581 2126-8480

e-mail: rejadel@yahoo.com.br

Recebido para publicação em01/06/2010

Aceito em 16/09/2010

\section{INTRODUÇÃO}

Onicomicoses são infecções nas unhas causadas por fungos como leveduras, dermatófitos ou outros fungos filamentosos, os quais constituem infecção superficial frequente na população imunocompetente ou imunossuprimida ${ }^{1}$.

Em população com imunossupressão, lesões de onicomicoses expressam características mais intensas e o agente infectante vir a causar doença disseminada ou fatal ${ }^{2}$. Em pacientes portadores do vírus da imunodeficiência humana (HIV), essa micose pode ocorrer em mais de $30 \%$ dos pacientes, principalmente quando a contagem de linfócitos T CD4 estiver abaixo de 400 células $/ \mathrm{mm}^{2,3}$. Outros fatores epidemiológicos relacionados são profissões que envolvem contato frequente das unhas com água e solo podendo contribuir para o estabelecimento da infecção fúngica ${ }^{4}$.

As apresentações clínicas das onicomicoses são classificadas de acordo com a localização, extensão e coloração das lesões. A mais comum é a onicomicose subungueal distal e lateral (OSDL) na qual predominam os dermatófitos com envolvimento ocasional por outro fungo filamentoso. A onicomicose superficial branca (OSB) é causada principalmente por T.mentagrophytes e, algumas vezes, por espécies de Acremonium ocorrendo comumente em pacientes com AIDS. A forma clínica distrófica total (ODT) é causada principalmente por dermatófitos e a onicomicose subungueal proximal (OSP) predomina nas unhas das mãos e é causada por espécies de Candida. Entretanto, em paciente portadores de AIDS essa forma clínica pode estar associada à dermatófitos ${ }^{5,6}$.

Pacientes HIV/AIDS são alvo constante das onicomicoses, fato frequentemente observado na prática médica ${ }^{7}$, contudo há escassez de trabalhos sobre o assunto. Dessa forma este trabalho tem como objetivo principal quantificar a ocorrência de onicomicoses em amostras de pacientes e identificar os agentes mais prevalentes. 


\section{MÉTODOS}

\section{Pacientes}

Foram avaliados 100 pacientes HIV/AIDS atendidos no Hospital Correia Picanço, referência em doenças infecto-contagiosas em Recife, Estado de Pernambuco, com sintomatologia e/ou lesões sugestivas de onicomicose.

A coleta das amostras clínicas foi realizada por raspado de lâmina ungueal ou leito subungueal após consentimento aprovação pelo Comitê de Ética em Pesquisa envolvendo seres humanos do Centro de Ciências da Saúde da Universidade Federal de Pernambuco CEP/ CCS/UFPE e pela Comissão de Ética Médica do Hospital Correia Picanço.

As amostras foram processadas para realização do exame direto, onde as escamas ungueais foram clarificadas com solução aquosa a $20 \%$ de hidróxido de potássio. Posteriormente, os espécimes clínicos foram semeados em duplicata no meio ágar Sabouraud (Difco) adicionado de $50 \mathrm{mg} / \mathrm{L}$ de cloranfenicol contido em placas de Petri, sendo mantidas às temperaturas de 30 e $37^{\circ} \mathrm{C}$ durante 15 dias para identificação dos agentes etiológicos ${ }^{8}$.

\section{Isolados}

A identificação das leveduras foi realizada segundo ${ }^{9}$ observação das características macroscópicas (aspecto, coloração e bordos das colônias), microscópicas (presença de pseudomicélio, micélio verdadeiro e produção de clamidosporos) e fisiológicas (assimilação de fontes de nitrogênio e carbono, fermentação de fontes de carbono e produção de urease). As leveduras também foram avaliadas através de meio CHROMagar ${ }^{\mathrm{tm}}$ Candida, o qual foi preparado de acordo com as instruções do fabricante e as placas foram mantidas a $4^{\circ} \mathrm{C}$ no escuro. Cada isolado foi subcultivado neste meio e incubado a $30^{\circ} \mathrm{C}$ por $48 \mathrm{~h}$. A leitura das placas e a interpretação dos resultados foram realizadas pela observação da morfologia e da pigmentação das colônias ${ }^{10}$.

Para identificação dos fungos filamentosos foram utilizados os critérios adotados por De Hoog cols ${ }^{11}$, Lacaz cols ${ }^{8}$ e Domisch cols $^{12}$ através da observação das características macroscópicas e microscópicas dos isolados.

\section{Considerações éticas}

Este estudo foi aprovado pelo Comitê de Ética em Pesquisa envolvendo seres humanos do Centro de Ciências da Saúde da Universidade Federal de Pernambuco CEP/CCS/UFPE e pela Comissão de Ética Médica do Hospital Correia Picanço

\section{RESULTADOS}

Dos pacientes com HIV/AIDS avaliados, 32 apresentaram distrofia ungueal com apresentações clínicas variadas. Dentre estes, 16 eram do sexo feminino com acometimento nas unhas de mãos em sete casos, pés em seis, e mãos/pés em três casos. Os 16 pacientes do sexo masculino apresentaram onicomicoses nas mãos em sete casos, pés em sete e nas unhas de mãos e pés em dois casos. A faixa etária variou de 27 a 59 anos no sexo feminino e de 22 a 57 anos, no masculino.

Dentre os 32 pacientes com manifestações clínicas de onicomicose, foram reconhecidas as apresentações clínicas típicas. Às formas clínicas clássicas foram associadas com hiperpigmentação e/ou hiperqueratose subungueal, com destaque nos casos de hiperqueratose no sexo feminino.
Das onicomicoses causadas por leveduras foram definidas taxonomicamente, através de todas as características compatíveis, os agentes etiológicos Candida albicans, C. guilliermondii, C. parapsilosis, C. tropicalis, Trichophyton rubrum, T. mentagroplytes. Aspegillus niger, Cylindrocarpon destructans, Fusarium solani, Scytalidium hialinum, S. japonicum e Phialophora reptans.

As colônias de leveduras que exibiram coloração verde-clara foram consideradas C. albicans e as azuis, C. tropicalis, de acordo com o método CHROMagar utilizado.

Houve associação de dois fungos na mesma lesão, como dois isolados de leveduras (C. albicans e $C$. tropicalis) nas unhas das mãos e um de levedura com fungo filamentoso (C. parapsilosis e T. rubrum), nas unhas dos pés. Foram também isoladas C. parapsilosis das unhas das mãos, C. destructans das unhas dos pés e T. rubrum das unhas de mãos e pés.

Ocorreu onicomicose por A. niger na unha das mãos de um paciente do sexo masculino e F. solani foi isolado de escamas ungueais dos pés de um paciente do sexo masculino e um paciente do sexo feminino. S. hyalinum e $S$.japonicum foram isolados de escamas ungueais dos pés de dois pacientes do sexo feminino, Phialophora reptans das unhas das mãos de um paciente do sexo masculino agricultor e C. destructans de escamas ungueais do pé de uma paciente com atividade do lar e jardinagem.

\section{DISCUSSÃo}

Nesta pesquisa, as lesões nas unhas das mãos foram mais frequentes em pacientes do sexo feminino que desempenhavam atividades do lar. Este fato pôde ser justificado, possivelmente, devido ao contato frequente com água e produtos químicos, concorrendo à instalação dos fungos ${ }^{4}$. Contudo, os resultados descritos no trabalho de Yamada ${ }^{13}$ acerca das micoses superficiais em pacientes HIV-positivos, a maior incidência de onicomicose ocorreu no sexo masculino, com maior acometimento das unhas dos pés.

Dos três pacientes do sexo masculino agricultores, dois eram portadores de onicomicose nas mãos e um em mãos e pés. Segundo Araújo $^{14}$ o tipo de ocupação e o contato com possíveis focos, favorecem o desenvolvimento das onicomicoses.

A apresentação clínica OSDL citada neste trabalho, foi também referida por Gupta cols ${ }^{2}$ ao trabalharem com pacientes com o $\mathrm{HIV}$, ocorrendo de forma isolada ou associada à SB. Cribier cols ${ }^{15}$ verificaram em 155 pacientes infectados com HIV leuconíquia e melanoníquia longitudinal como apresentações clínicas mais freqüentes de onicomicose neste grupo de pacientes. Entretanto, Baran cols ${ }^{16}$ ao avaliarem imunocompetentes, observaram como apresentações clínicas a onicomicose subungueal distal e lateral, superficial, subungueal proximal, endonix e onicomicose distrófica total, e ressaltaram a possibilidade de associações entre estas formas.

A diversidade de fungos relacionados à etiologia de diferentes formas clínicas de onicomicose sugere que deve ser declinada uma atenção a esta micose uma vez que a mesma pode evoluir para quadros mais graves em imunossuprimidos ${ }^{17}$. Segundo Johnson ${ }^{18}$ infecções crônicas podem favorecer uma porta de entrada para infecções mistas e subsequentes infecções fúngicas invasivas originadas de onicomicose. Neste sentido, Hennequin cols ${ }^{19}$ descrevem um caso fatal de infecção sistêmica secundária por Fusarium com provável origem de infecção ungueal grave. Estes autores consideram onicomicose causada por agentes emergentes como doença potencialmente grave em paciente com HIV. 
Surjushe cols ${ }^{20} \mathrm{em}$ trabalho com onicomicose em pacientes com $\mathrm{HIV}$, indicaram como de maior incidência A. niger, Cladosporium sp, S. hyalinum, Penicillium sp e Gymnoascus dankaliensis. No entanto, Cribier cols ${ }^{15}$ destacam dermatófitos como os principais agentes causadores de onicomicose em pacientes com HIV, assim como Graham cols ${ }^{21}$ que referem T. rubrum seguido por T. mentagrophytes, T. tonsurans, Epidermophytonfloccosum, e C. albicans como os agentes mais comuns de onicomicose em infectados com HIV.

Candida albicans destacou-se neste trabalho como a espécie mais frequente das onicomicoses, seguida de dermatófitos e de outros fungos filamentosos considerados emergentes nos pacientes HIV/aids. Também Ginter cols ${ }^{22}$, ressaltam a predominância de onicomicose por dermatófitos, seguidos de leveduras e outros fungos filamentosos, entretanto, em imunocompetentes.

As associações entre agentes etiológicos nas onicomicoses são raramente citadas. Contudo, Rugeles cols ${ }^{17}$ observaram associação de levedura e fungos filamentosos, além de Yamada cols ${ }^{13}$ que citam três casos de dermatófito associado com levedura, um de fungo filamentoso com levedura e um dermatófito com outro fungo filamentoso. Estes mesmos autores, com relação à localização da lesão, destacaram as lesões nas unhas dos pés.

Os casos dos quais foram isolados Aspergillus como agente etiológico das lesões ungueais não corroboram com a freqüência de onicomicose podal citada por Tosti cols ${ }^{23}$.

Assim como verificado neste trabalho, outros fungos filamentosos foram causa de onicomicoses em HIV/AIDS tais como espécies de Scytalidium, Fusarium, Phialophora e Cylindrocarpon, os quais são mencionados por diversos autores como capazes de invadir e degradar a queratina da unha ${ }^{24-26}$.

Do material ungueal de um paciente, não foi obtida cultura de fungo, embora o exame direto tenha revelado filamentos micelianos septados, artrosporados e células de leveduras. Os procedimentos laboratoriais de exame direto e cultura devem ser realizados para o diagnóstico de onicomicose, uma vez que existem casos que o exame direto define a ocorrência dessa micose. $\mathrm{O}$ rápido crescimento bacteriano, o uso de medicamentos específicos, as exigências do fungo in vitro e o inóculo pobre em estruturas fúngicas viáveis, podem ter sido causas da não obtenção de cultura.

As manifestações clínicas ungueais apenas poderão ser indicadas como onicomicose após o diagnóstico laboratorial micológico e, desta forma, ser iniciado o tratamento específico para o agente causal ${ }^{27}$.

\section{AGRADECIMENTOS}

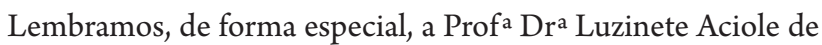
Queiroz in memorian.

\section{CONFLITO DE INTERESSE}

Os autores declaram não haver nenhum tipo de conflito de interesse no desenvolvimento do estudo.

\section{SUPORTE FINANCEIRO}

Este trabalho foi apoiado pelo Conselho Nacional de Desenvolvimento Científico e Tecnológico $(\mathrm{CNPq})$ e pelo Programa de Pós-Graduação em Biologia de Fungos (PPGBF) da Universidade Federal de Pernambuco.

\section{REFERÊNCIAS}

1. Balleste R, Mousqués N, Gezuele E. Onicomicosis. Revisión del tema. An Asoc Quim Farm Uruguay 2003; 19:93-106.

2. Gupta Ak, Taborda P, Taborda V, Gilmour J, Rachlis A, Salit I, et al. Epidemiology and prevalence of onychomycosis in HIV-positive individuals. Int J Dermatol 2000; 39:746-753.

3. Dahdah MJ, Scher RK. Onychomycosis - an overview. US: Dermatology review; 2006.

4. Ellabib MS, Agaj M, Khalifa Z, Kavanagh K. Yeasts of the genus Candida are the dominant cause of onychomycosis in Libyan women but not men: results of a 2 year surveillance study. Br J Dermatol 2002; 146:1038-1041.

5. Baran R, Berker D, Dawber R. Doenças da unha: tratamento clínico e cirúrgico. Rio de Janeiro: Revinter; 2000.

6. Roberts DT, Evans EGV, Allen R. Occurrence of onychomycosis among patients attended in dermatology offices in the city of Rio de Janeiro, Brazil. An Bras Dermatol 2003; 78:299-308.

7. Vender RB, Lynde CW, Poulin Y. Prevalence and epidemiology of onychomycosis. J Cutan Med Surg. 2006; 10:28-33.

8. Lacaz CS, Porto E. Tratado de Micologia Médica. São Paulo: Editora Sarvier; 2002.

9. Barnett JA, Paine RW, Yarrow D. Yeasts: Characteristics and Identification. Cambridge: Cambridge University Press; 2000.

10. Odds FC, Bernaerts R. CHROMagar Candida, a new differential isolation medium for presuntive identification of clinically important Candida species. J Clin Microbiol 1994; 32:1923-1929.

11. De Hoog GS, Guarro J, Gené J, Figueiras MJ. Atlas of Clinical Fungi. $2^{\text {nd }}$ ed. The Netherlands: Centraalbureau Voor Schimmelcultures Utrecht; 2000.

12. Domisch KH, Gams W, Anderson TH. Compendium of Soil Fungi. London: Academic Press; 1980.

13. Yamada CK, Bohnenstengel E, Mendes AVTO, Sabongi VPG, Meira MCAM. Incidence of dermatophytosis and candidosis in HIV positive patients. An Bras Dermatol 2000; 75:157-163.

14. Araújo AJG, Bastos OMP, Souza MAJ, Oliveira JC. Onychomycosis caused by emergent fungi: clinical analysis, diagnosis and revision. An Bras Dermatol 2003; 78:445-455.

15. Cribier B, Mena ML, Rey D, Partisani M, Fabien V, LangJM, et al. Nail changes in patients infected with human immunodeficiency virus. A prospective controlled study. Arch Dermatol 1998; 134:1216-1220.

16. Baran R, Hay RJ, Tosti A, Haneke E. A new classification of onychomycosis. Br J Dermatol. 1998; 139:567-571.

17. Rugeles MJ, Vasqués JL, Jaramilo E, Orozco B, Estrada S, Ospina S. Etiología y características clínicas de la onicomicosis en un grupo de pacientes inmunosuprimidos. Infectio Rev Asociación Colombiana Infectol 2001; 5:7-13.

18. Johnson RA. HIV Disease: Mucocutaneous fungal infections in HIV disease clinics in dermatology. 2000; 18:411-422.

19. Hennequin C, Lavarde V, Poirot JL, Rabodonirina M, Datry A, Aractingi S, et al. Invasive Fusarium infections: a retrospective survey of 31 cases. J Med Vet Mycol. 1997; 35:107-114.

20. Surjushe A, Kamath R, Oberai C, Saple D, Thakre M, Dharmshale S, et al. A clinical and mycological study of onychomycosis in HIV infection. Indian J Dermatol 2007; 73:397-401.

21. Graham ERJ, Charlene LB, Loan T, Raza A. The prevalence of dermatophyte infection in patients infected with human immunodeficiency virus. Int J Dermatol 2008; 47:339-343.

22. Ginter G, Rieger E, Heigl K, Propst E. Increasing frequency of onychomycosis - is there a change in the spectrum of infections agents? Mycoses. 1996; 39:118-22.

23. Tosti A, Piraccini BM, Lorenzi S. Onychomycosis caused by nondermatophytic molds: clinical features and response to treatment of 59 cases. J Am Acad Dermatol 2000; 42:217-224.

24. Oyeka CA, Gugnani HC. Keratin degradation by Scytalidium species and Fusarium solani Mycoses. 1998; 41:73-76.

25. López-Jodra, Torres-Rodríguez. Unusual fungal species causing onychomycosis. Rev Iberoam Micol 1999; 16:11-15.

26. Duggan JM, Wolf MD, Kauffman CA. Phialophora verrucosa infection in an AIDS patient. Mycoses. 1995; 38:215-218.

27. Ramos-Silva M, Lima CMO, Schechtman RC, Trope BM, Carneiro S. Superficial mycoses in immunodepressed patients (AIDS). Clin Dermatol 2010; 28:217-225. 